\title{
Sistem Kendali On/Off Motor Induksi Pompa Air Dengan Histerisis dapat Diprogram
}

\author{
NANA SUBARNA \\ Institut Teknologi Nasional \\ Email : nana.sbn@gmail.ac.id
}

\begin{abstract}
ABSTRAK
Pengaturan motor induksi pompa air biasanya menggunakan saklar tekanan dengan histerisis. Kekurangan dari transduser ini adalah lebar histerisis yang terbatas dan penggunaan saklar mekanik untuk pengaturannya sehingga cepat aus dan berisik. Untuk mengatasinya dengan mengganti saklar mekanik dengan saklar elektrik triac dan penggunaan sistem mikrokontroler untuk mengatur waktu on/off triac dan memanipulasi karakteristik saklar mekanik. Sistem terdiri dari saklar elektrik triac yang dikontrol sistem mikrokontroler dengan penyalaan sudut phasa. Besarnya sudut penyalaan ditentukan berdasarkan waktu on/off saklar tekanan yang ditentukan oleh debit air yang keluar. Dengan mengatur sudut penyalaan, waktu histerisis on/off dapat diatur untuk debit air yang berbeda. Sistem Kendali On/Off dapat digunakan untuk memanipulasi dan mengubah karakteristik saklar tekanan dari $0.75 \mathrm{~s}$ - 12s menjadi 6.2s - 10.1s untuk debit air 2 - 11 LPM dan waktu rata-rata on, ton_off $=7.4 \mathrm{~s}$ dibanding ton_kon $=2.94 \mathrm{~s}$, sehingga sistem pompa air kurang berisik suaranya.
\end{abstract}

Kata kunci : saklar tekanan, histerisis, saklar mekanik, saklar elektrik, waktu on/off, manipulasi, sudut phase, Ipm.

\begin{abstract}
To regulate pressure in the water pump motor usually uses a pressure switch with hysteresis. The disadvantages of this transducer are the limited width of the hysteresis and the use of mechanical switching its could wear out and noisy. To overcome this by replacing the mechanical switch with a triac electric switch and using a microcontroller system to control on / off time the triac and manipulate the characteristics of the pressure switch. The system consists of a triac electric switch which is controlled by a microcontroller system with a phase angle firing. The magnitude of the phase angle is determined based on the on / off time of the pressure switch which is depend on the water discharge from the pump. By setting the phase angle firing, the hysteresis on / off time can be set for different water discharge. The On /Off Control System can be used to manipulate and change the pressure switch characteristics from $0.75 \mathrm{~s}-12 \mathrm{~s}$ to $6.2 \mathrm{~s}-10.1 \mathrm{~s}$ for water discharge 2 - 11 LPM and average time ton_off $=7.4 \mathrm{~s}$ over ton_kon $=2.94 \mathrm{~s}$, so the water pump system has less noise.
\end{abstract}

Keywords : Pressure switch, hysteresis, mechanical switching, electric switch, waktu on/off, manipulate, phase angle, Ipm. 


\section{PENDAHULUAN}

Penggunaan motor induksi untuk pompa air di rumah tangga banyak digunakan. Pada makalah ini akan dibahas tentang sistem kendali on/off motor induksi pompa air 1 phasa dengan daya $125 \mathrm{~W}$. Sistem pompa air terdiri dari motor induksi, saklar tekanan dan akumulator, lihat Gambar 1. Saklar tekanan berupa saklar on/off mekanik yang berfungsi sebagai pengatur kerja motor induksi berdasarkan tekanan air dalam pompa dan penggunaan debit air. Saklar on pada $1.1 \mathrm{kgf} / \mathrm{cm}^{2}$ dan off pada $1.8 \mathrm{kgf} / \mathrm{cm}^{2}$. Akumulator berupa ruang bertekanan udara yang berfungsi sebagai penstabil tekanan air.

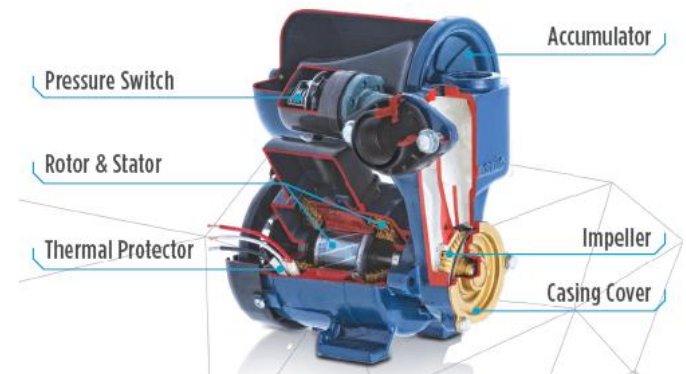

\section{Gambar 1. Bagian motor induksi pompa air}

(Sumber : Panasonic, 2012).

Umumnya sistem pompa air konvensinal tidak dilengkapi pengatur daya listrik. Pada pemakaian debit air rendah dan tinggi, daya yang digunakan sama sehingga terjadi pemborosan energi. Selain pemborosan energi, saklar mekanik dan motor pompa air on dan off hampir bersamaan sehingga menimbulkan suara yang cukup berisik dan terjadinya gangguan listrik pada jala-jala listrik PLN karena arus transien on/off tersebut. Untuk mengatasi masalah suara berisik dan gangguan listrik, biasanya air yang akan dipakai ditampung dulu di atas toren tangki air. Cara ini cukup efektif, debit air bisa diatur dengan mudah, suara berisik dan gangguan listrikpun hilang, tetapi kekurangannya adalah tekanan air kurang besar sehingga diperlukan pompa tambahan untuk menaikkan tekanan air. Kekurangan lainnnya adalah saklar tekanan menggunakan saklar mekanik dimana kontaknya dapat aus yang disebabkan oleh adanya arc dan glow discharge (Ott, 2009) yang terjadi saat kontak on/off.

Pada makalah ini akan dibahas tentang sistem kendali daya motor pompa air dengan mengatur tegangan motor induksi dengan pengaturan sudut penyalaan saklar elektrik triac dengan metoda PWM (pulse width modulation) menggunakan sistem mikrokontroler. Sistem mikrokontroler dan triac berfungsi sebagai pengganti saklar pada saklar tekanan dengan histerisis yang dapat diatur. Pengaturan waktu histerisis berdasarkan pada waktu on/off dari saklar tekanan. Dengan mengatur waktu on/off triac menggunakan sistem mikrokontroler, maka daya dan waktu histerisis pompa air dapat diatur dengan lebih mudah.

\section{PERANCANGAN SISTEM}

\subsection{Metode Perancangan}

Sistem bekerja berdasarkan waktu on dan waktu off dari saklar tekanan akibat perubahan tekanan di dalam pompa air ketika air digunakan. Untuk mengembangkan sistem kendali pompa air berbasis mikrokontroler digunakan komponen berikut : sistem mikrokontroler, saklar tekanan, zero crossing detector, saklar electrik, key pad dan LCD, lihat Gambar 2. 


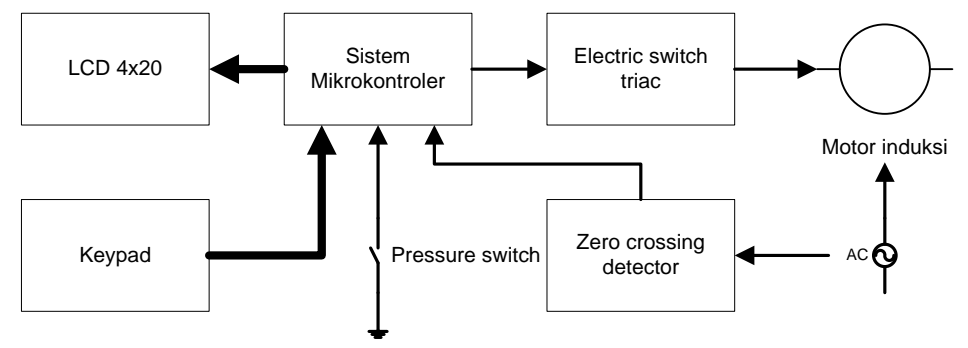

\section{Gambar 2. Sistem Kendali On/Off Motor Induksi Pompa Air Dengan Histerisis Dapat Diprogram}

Pada umumnya sistem pompa air konvensional, menggunakan saklar tekanan yang terdiri dari dua bagian yaitu bagian sensor tekanan air dan bagian actuator on/off berupa saklar mekanik, lihat Gambar 3. Pada sistem kendali pompa air yang akan dikembangkan, saklar tekanan dirubah fungsinya menjadi sensor elektro-mekanik berupa sensor tekanan air dan sensor posisi on/off. Fungsi actuator saklar on/off diganti dengan saklar electric berupa triac.

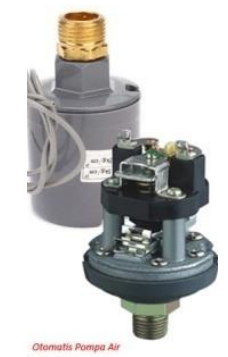

\section{Gambar 3. Saklar tekanan pompa air}

(Sumber : Wapannuri, 2017).

Sensor posisi on/off digunakan untuk mengetahui lamanya waktu on dan waktu off motor induksi yang besarnya bergantung pada tekanan pompa air dan debit air yang digunakan. Data on dan off ini digunakan untuk menentukan besarnya sudut penyalaan triac yang akan menentukan besarnya daya (Desai, 2016), (STMicroelectronics, 2007) motor induksi, lihat Gambar 4.

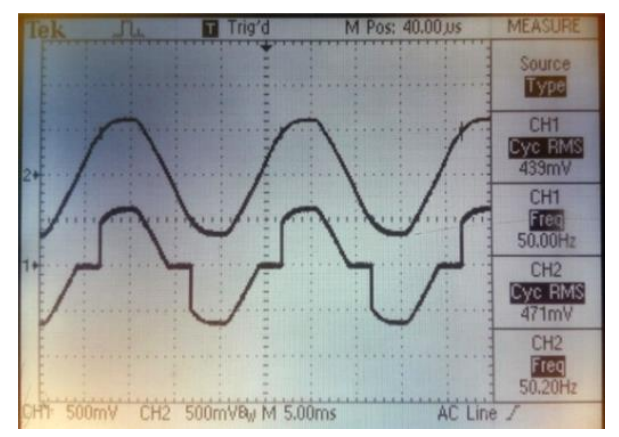

\section{Gambar 4. Pengaturan daya motor induksi dengan pengaturan sudut penyalaan} triac.

\subsection{Zero Crossing Detector (Gupta, 2013).}

Untuk penentuan tegangan $0 \mathrm{~V}$, sebagai sudut awal perhitungan penyalaan triac diambil dari tegangan nol jala-jala listrik pada saat perubahan phasa tegangan dengan menggunakan rangkaian zero crossing detector, lihat Gambar 5. Rangkaian terdiri dari penyearah tegangan $A C\left(D_{1}-D_{4}\right)$ dan pembagi tegangan $R_{1}, R_{2}$ dan $R_{3}$ untuk mengisi muatan kapasitor $C_{1}$ melalui 
$D_{5} . Q_{1}$ berfungsi sebagai komparator tegangan yang hanya akan aktif jika tegangan pada $C_{1}$ lebih besar dari tegangan rata-rata jala-jala listrik yang telah disearahkan dan diturunkan dengan pembagi tegangan. Besarnya arus yang mengalir pada dioda optocoupler dibatasi oleh $\mathrm{R}_{4}$. Output optocoupler digunakan sebagai sinyal interupsi untuk awal perhitungan sudut penyalaan triac.

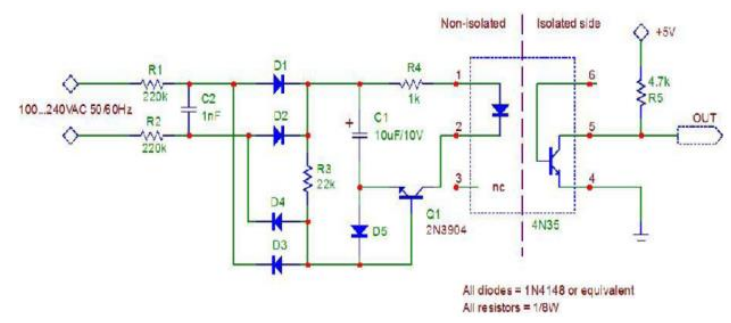

\section{Gambar 5. Rangkaian pendeteksi tegangan nol}

(Sumber : Gupta, 2013).

Untuk pengganti aktuator saklar on/off digunakan non zero cross SSR (solid state relay) dengan input dioda optocoupler S202T02 lihat Gambar 6.

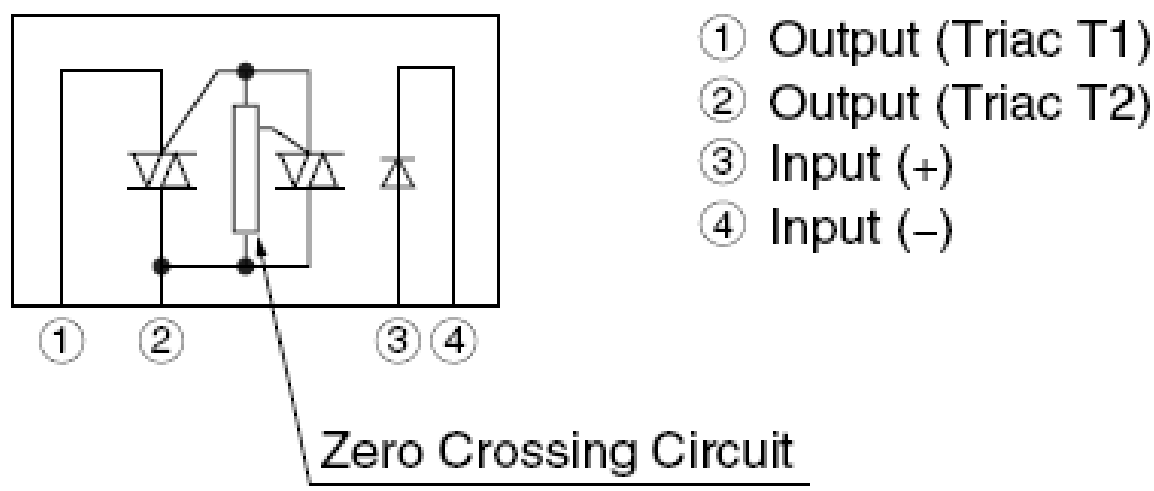

\section{Gambar 6. Rangkaian non zero cross SSR (solid state relay) dengan S202T02}

(Sumber : SHARP, 2004).

\subsection{Sistem Mikrokontroler}

Sistem mikrokontroler yang digunakan adalah mikrokontroler ATmega8535 dari Atmel dengan fitur arsitektur prosesor RISC, 32 × 8 General Purpose Working Registers dan 8K Bytes of In-Sistem Self Programmable Flash memory (Atmel, 2006). Perangkat lunak bekerja berdasarkan data waktu on dan off saklar tekanan yang disampling tiap 2s sekali.

Hubungan waktu on dan \%daya motor menggunakan persamaan linear yang didapat secara empiris dari hasil pengukuran waktu on dan waktu off untuk \%daya dari 5\% - 95\%. Lebih jauh dibahas pada bagian pengukuran. Operasi I/O menggunakan mode interupsi dimana rangkaian zero crossing detector akan menghasilkan pulsa dengan siklus kerja $90 \%$ setiap $10 \mathrm{~ms}$.

Untuk tahap awal sistem mikrokontroler diprogram hanya untuk membangkitan pulsa trigger untuk SSR dengan sudut penyalaan variable dari 5\% - 95\% $\left(9^{\circ}-171^{\circ}\right)$ untuk menggerakkan pompa air untuk pengukuran waktu on dan off saklar tekanan sebagai fungsi dari debit air. Dari hasil pengukuran ini diharapkan didapat hubungan antara waktu on dan off dengan jumlah pemakain air yang keluar dari pompa air. 
Secara garis besar diagram alir dari program yang dikembangkan untuk sistem kendali on/off ini dapat dilihat pada Gambar 7.
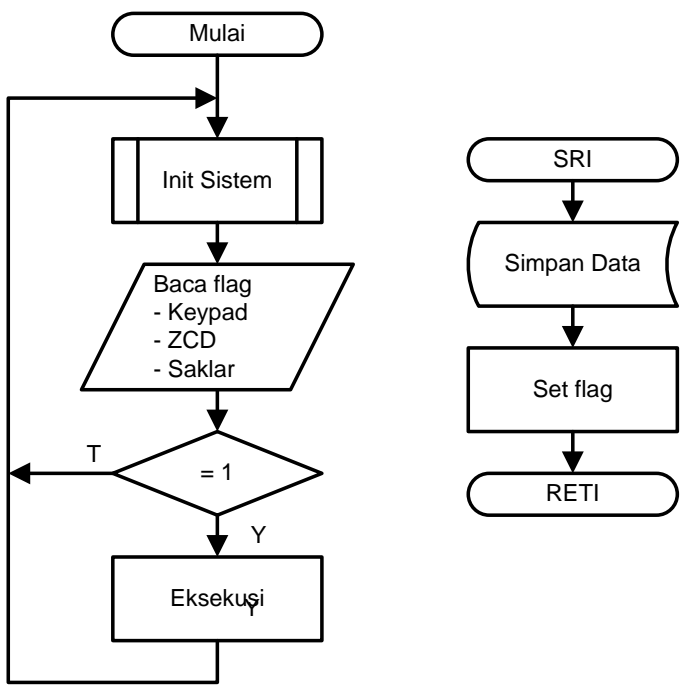

\section{Gambar 7. Diagram alir program yang dikembangkan untuk sistem kendali on/off.}

\section{PENGUKURAN}

Alat ukur yang digunakan dalam pengukuran ini :

- Liquid Rotameter dengan batas ukur 2 - 18 LPM.

- Digital Real-Time Oscilloscopes TDS210 dari Tektronix.

- Clamp On Power Hi Tester 3286-20 dari Hioki.

\subsection{Pengukuran Waktu On dan Off}

Tujuan pengukuran adalah untuk mendapatkan karakteristik dari sistem pompa air konvensional dengan saklar tekanan. Ada 2 jenis pengukuran yang dilakukan yaitu pengukuan dengan daya motor penuh dan daya motor dengan sudut penyalaan yang dapat diatur.

\subsection{Pengukuran Waktu On dan Off Untuk Daya Motor Penuh}

Pengukuran dilakukan dengan mengalirkan air pada rangkaian aliran air tertutup yang digerakkan dengan motor induksi pompa air, lihat Gambar 8. Dengan melakukan pengaturan debit air yang keluar dari pompa air kita dapat mengetahui berapa waktu on dan off saklar tekanan. Untuk alat ukur flowmeter digunakan flow meter air jenis Rotameter. 


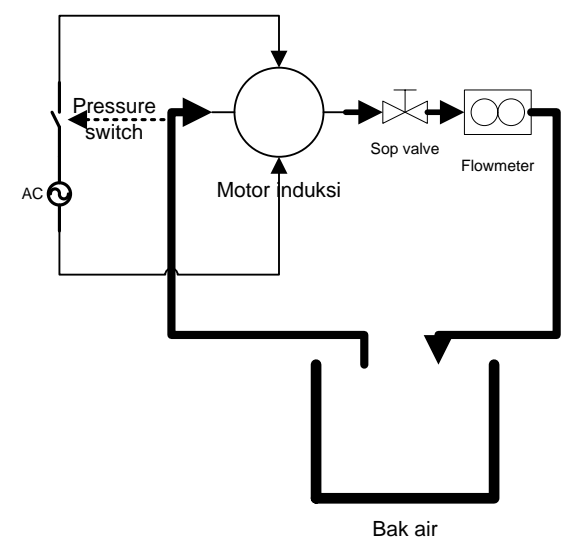

Gambar 8. Skema pengukuran Waktu On dan Off untuk daya motor penuh.

Dari hasil pengukuran didapat table berikut :

Tabel 1 Pengukuran waktu on dan off saklar tekanan dengan sudut penyalaan $100 \%$.

\begin{tabular}{|l|l|l|l|}
\hline No. & $t_{\text {on }}(\mathrm{S})$ & $\mathrm{t}_{\text {off }}(\mathrm{s})$ & $\mathrm{Q}(\mathrm{Ipm})$ \\
\hline 1 & 0.75 & 7.50 & 2.0 \\
\hline 2 & 1.25 & 7.50 & 2.0 \\
\hline 3 & 1.50 & 5.00 & 3.0 \\
\hline 4 & 1.50 & 3.75 & 4.0 \\
\hline 5 & 1.50 & 2.75 & 5.0 \\
\hline 6 & 1.75 & 2.25 & 6.0 \\
\hline 7 & 2.25 & 2.00 & 7.0 \\
\hline 8 & 2.38 & 1.75 & 8.0 \\
\hline 9 & 3.00 & 1.50 & 9.0 \\
\hline 10 & 4.50 & 1.00 & 10.0 \\
\hline 11 & 12.00 & 1.00 & 11.0 \\
\hline
\end{tabular}

Dari data ton dan toff, hanya data ton yang digunakan. Untuk mengetahui hubungan antara ton dan debit air, digunakan aplikasi Microsoft Excell. Dari pengamatan Table 1, diketahui hanya untuk waktu ton dari $0.75 \mathrm{~s}-4.50 \mathrm{~s}$ yang bisa didekati dengan persamaan linear. 


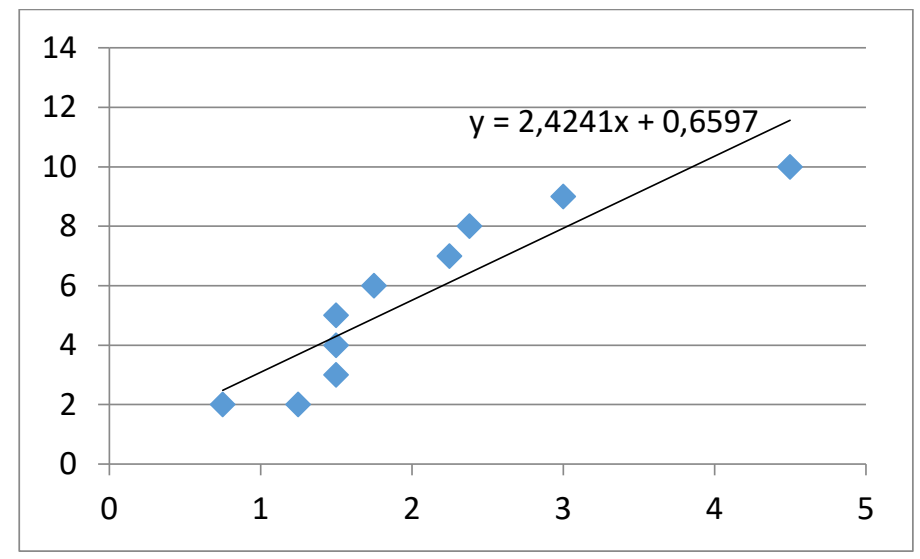

Gambar 9. Kurva linearisasi hubungan waktu ton (s) dan debit air (LPM) daya penuh.

\subsection{Pengukuran Waktu On dan Off Untuk Daya bervariasi.}

Skema pengukuran sama dengan pengukuran Waktu On dan Off Untuk Daya penuh. Pengukuran waktu on dan off dilakukan dengan pengaturan prosentase daya motor prosentase daya dari 50\% - 95\%. Tabel 2 bersisi data pengukuran ton dan toff untuk prosentase tersebut. Pengukuran di bawah $50 \%$ motor berputar seperti kurang daya.

Hubungan ton dan daya didekati dengan persamaan linear didapat persamaan berikut :

$$
y=27.74 x-37.61
$$

dimana $\mathrm{y}=$ prosentase daya dan $\mathrm{x}=$ waktu ton dari saklar tekanan. Persamaan ini digunakan untuk model pengaturan motor.

Tabel 2 Pengukuran waktu on dan off saklar tekanandengan sudut penyalaan bervariasi.

\begin{tabular}{|l|l|l|l|l|l|}
\hline No. & $\mathrm{t}_{\text {on }}(\mathrm{S})$ & $\mathrm{t}_{\text {off }}(\mathrm{s})$ & $\mathrm{Ipm}$ & $\mathrm{dc}(\%)$ & Daya \\
\hline 1 & 3.25 & 1.3 & 5.50 & 50 & 146 \\
\hline 2 & 3.50 & 1.3 & 7.00 & 55 & 151 \\
\hline 3 & 3.30 & 1.1 & 8.50 & 60 & 155 \\
\hline 4 & 3.70 & 1.1 & 9.25 & 65 & 162 \\
\hline 5 & 3.90 & 1.0 & 9.75 & 70 & 167 \\
\hline 6 & 4.00 & 0.9 & 10.00 & 75 & 170 \\
\hline 7 & 4.00 & 0.9 & 10.25 & 80 & 175 \\
\hline 8 & 4.10 & 0.9 & 10.75 & 85 & 175 \\
\hline 9 & 6.50 & 0.8 & 11.00 & 90 & 176 \\
\hline 10 & 7.40 & 0.9 & 11.00 & 95 & 175 \\
\hline & & & & 100 & 177 \\
\hline
\end{tabular}




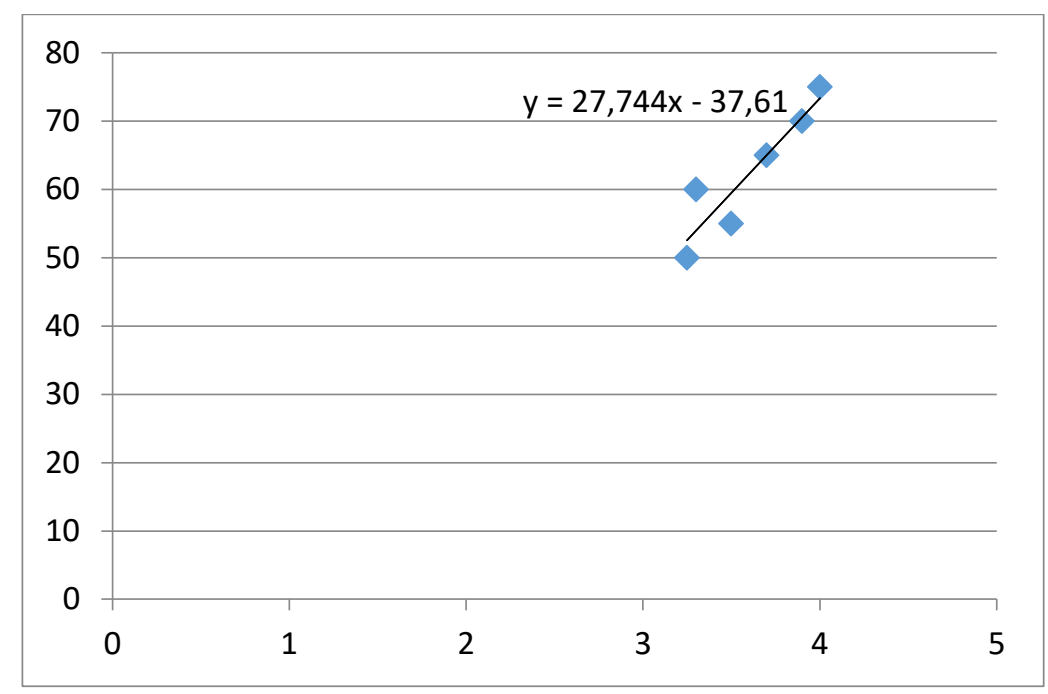

Gambar 10. Kurva linearisasi hubungan waktu ton (s) dan debit air (LPM) daya bervariasi

Hubungan ton dan daya didekati dengan persamaan linear didapat persamaan berikut :

$$
y=27.74 x-37.61
$$

dimana $\mathrm{y}=$ prosentase daya dan $\mathrm{x}=$ waktu ton dari saklar tekanan. Persamaan ini digunakan untuk model pengaturan motor.

\subsection{Pengukuran Waktu On dan Off Untuk Sistem Kendali On/Off}

Untuk menguji ketercapaian sistem kendali on/off yang dikembangkan dilakukan pengukuran waktu on dan waktu off dari saklar tekanan dan sinyal kontrol triac. Untuk prosedur pengukuran berbeda dengan pengukuran sebelumnya karena sistem yang diukur adalah sistem kendali on/off dengan feed back dari saklar tekanan yang telah dimanipulasi oleh sistem mikrokontroler, lihatcgbr. Dari hasil pengukuran didapat hasil table 3.

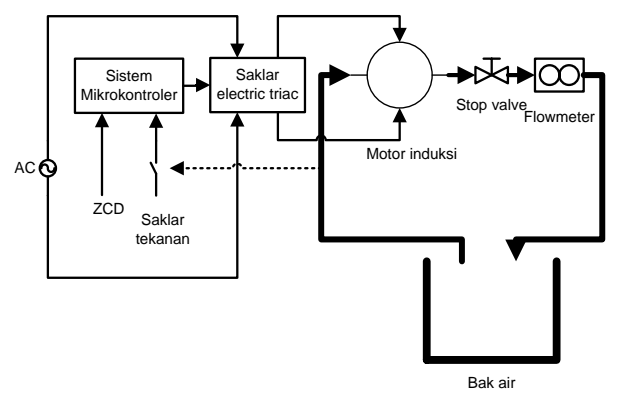

Gambar 11. Skema pengukuran aktu on dan off sistem kendali on/off.

Tabel 3. Pengukuran Waktu On dan Off Untuk Sistem Kendali On/Off

\begin{tabular}{|r|r|r|r|r|r|}
\hline \multirow{2}{*}{ No. } & \multicolumn{2}{|c|}{ Saklar tekanan } & \multicolumn{2}{|c|}{ Triac } & \\
\cline { 2 - 6 } & \multicolumn{1}{|c|}{ ton } & \multicolumn{1}{c|}{ toff } & \multicolumn{1}{c|}{ ton } & \multicolumn{1}{c|}{ toff } & \multicolumn{1}{c|}{ LPM } \\
\hline 1 & 6.2 & 17.4 & 6.0 & 17.6 & 2 \\
\hline 2 & 6.2 & 13.2 & 6.4 & 12.0 & 3 \\
\hline 3 & 6.6 & 11.0 & 6.6 & 10.6 & 4 \\
\hline 4 & 6.6 & 8.8 & 7.8 & 8.6 & 5 \\
\hline
\end{tabular}




\begin{tabular}{|r|r|r|r|r|r|}
\hline 5 & 6.0 & 7.0 & 7.8 & 7.0 & 6 \\
\hline 6 & 7.6 & 7.2 & 7.4 & 7.4 & 7 \\
\hline 7 & 7.6 & 6.8 & 8.0 & 6.6 & 8 \\
\hline 8 & 8.2 & 6.4 & 8.2 & 6.4 & 9 \\
\hline 9 & 9.0 & 6.0 & 9.0 & 6.0 & 10 \\
\hline 10 & 10.1 & 6.0 & 10.8 & 6.0 & 11 \\
\hline
\end{tabular}

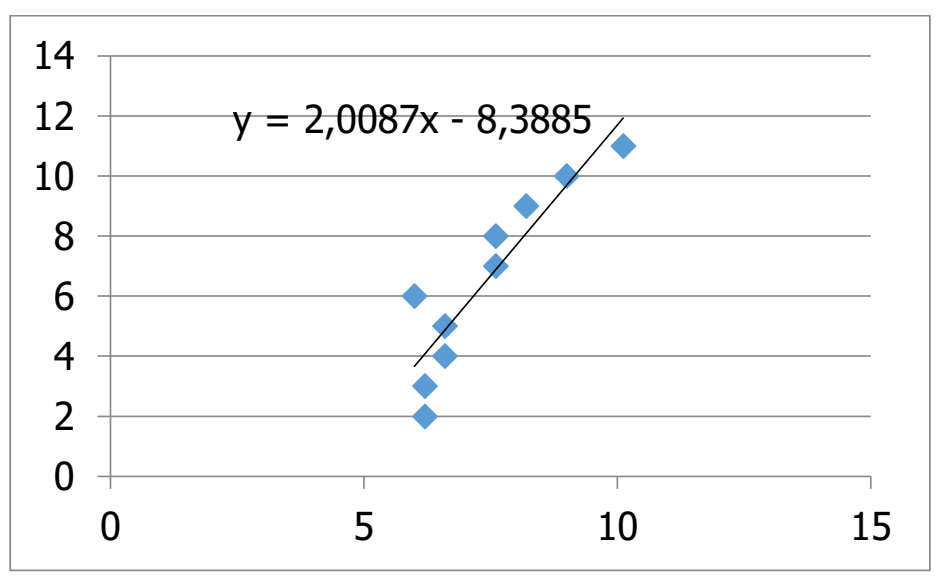

\section{Gambar 12. Kurva linearisasi hubungan waktu ton (s) dan debit air (LPM) sistem kendali on/off.}

\section{HASIL PENGAMATAN}

Dari hasil pengamatan terhadap sistem kendali motor induksi pompa air diketahui bahwa sistem sudah dapat bekerja dengan baik dimana fungsi saklar tekanan sebagai sensor dan actuator sudah dapat diganti dengan sensor tekanan on/off dan sakalar elektrik triac. Dari hasil perbandingan table 1 dengan table 3 dan gbr. 9 dengan gbr. 12, dapat diketahui :

- Sistem bekerja pada range waktu on dan off yang berbeda

- Linearitas sistem pompa air dengan sistem kendali on/off lebih baik

- Berdasarkan perhitungan persamaan (2), sistem kendali on/off masih bekerja dengan daya penuh waktu on dan belum bekerja dengan daya bervariasi. Ini dapat dilihat bahwa berdasarkan persamaan (2), daya $95 \%$ dapat dicapai pada ton $=4.78 \mathrm{~s}$ sedangkan dari semua pengukuran ton $>6.0 \mathrm{~s}$

- Dengan waktu rata-rata on sistem konvensional, ton_kon $=2.94 \mathrm{~s}$ dan sistem kendali on/off, ton_off $=7.4 \mathrm{~s}$, maka sistem kendali on/off suaranya kurang berisik disbanding sistem konvensional.

Tabel 4 Perbandingan sistem lama (open loop) dengan sistem kendali on/of

\begin{tabular}{|c|c|c|c|}
\hline \multicolumn{2}{|c|}{ Sistem open loop } & \multicolumn{2}{c|}{$\begin{array}{c}\text { Sistem close } \\
\text { loop }\end{array}$} \\
\hline ton & LPM & ton & LPM \\
\hline 0.75 & 2 & & \\
\hline 1.25 & 2 & 6.2 & 2 \\
\hline 1.50 & 3 & 6.2 & 3 \\
\hline 1.50 & 4 & 6.6 & 4 \\
\hline 1.50 & 5 & 6.6 & 5 \\
\hline
\end{tabular}




\begin{tabular}{|c|c|c|c|}
\hline 1.75 & 6 & 6.0 & 6 \\
\hline 2.25 & 7 & 7.6 & 7 \\
\hline 2.38 & 8 & 7.6 & 8 \\
\hline 3.0 & 9 & 8.2 & 9 \\
\hline 4.5 & 10 & 9.0 & 10 \\
\hline 12.0 & 11 & 10.1 & 11 \\
\hline
\end{tabular}

\section{KESIMPULAN}

Sistem Kendali On/Off Motor Induksi Pompa Air adalah sistem berbasis mikrokontroler ATmega8535 dari Atmel yang memanfaatkan kemudahan dalam pemrogramman fungsionalnya. Kemudahan ini digunakan untuk memanipulasi dan mengubah karakteristik saklar tekanan untuk waktu ton $0.75 \mathrm{~s}-12 \mathrm{~s}$ menjadi $6.2 \mathrm{~s}-10.1 \mathrm{~s}$ untuk debit air $2-11$ LPM dan dengan cara memanipulasi karakteristik ini karakteristik sistem menjadi lebih linear.

Dengan waktu rata-rata on yang lebih besar, ton_off $=7.4 \mathrm{~s}$ disbanding ton_kon $=2.94 \mathrm{~s}$, sistem kendali on/off motor induksi pompa air kurang berisik suaranya.

\section{UCAPAN TERIMA KASIH}

Penulis mengucapkan terima kasih kepada Ir. Banang Mulya Permana sebagai seorang konsultan profesional yang telah membantu penulis dalam pengembangan perangkat lunak sistem. Ir. Banang Mulya Permana dapat dikontak di bmpermana@gmail.com

\section{DAFTAR RUJUKAN}

\section{Rujukan Buku:}

Ott, Henry W. (2009). Electromagnetic Compatibility Engineering. New Jersey: John Wiley \& Sons, Inc.

\section{Rujukan Jurnal:}

Desai, Yash (2016). AC Phase Firing Circuit Using Microcontroller. International Journal of Advance Engineering and Research Development. Volume 3, Issue 3.

Gupta, Ankita et all (2013). An Efficient Approach to Zero Crossing Detection Based On OptoCoupler. Int. Journal of Engineering Research and Applications www.ijera.com ISSN : 2248-9622, Vol. 3, Issue 5, pp.834-838.

\section{Rujukan Aplikasi:}


STMicroelectronics (2007). Universal motor speed control and light dimmer with TRIAC and ST7LITE microcontroller. AN2263 Application note

\section{Rujukan Sumber Online :}

Atmel (2006). ATmega8535. Retrieved from ww1.microchip.com.

Panasonic (2012). Waterpump Catalogue.Retrieved from www.panasonic.com.

SHARP (2004, Apr. 28). S202T01 Series, Triac output SSR. Retrieved from www.quartz1.com.

Wapannuri(2017). Otomatis pompa air. Retrieved from wapannuri.com. 
Tuliskan Nama Penulis sebagai header halaman genap 